\title{
Correction to: Influence of cancer and acute inflammatory disease on taste perception: a clinical pilot study
}

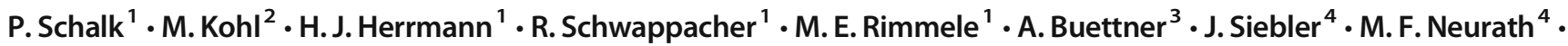 \\ Y. Zopf ${ }^{1}$
}

Published online: 13 February 2020

(C) Springer-Verlag GmbH Germany, part of Springer Nature 2020

\section{Correction to: Supportive Care in Cancer (2019) 27:1579.} https://doi.org/10.1007/s00520-017-3898-y

The Acknowledgement Statement was incorrect in the original publication of this article [1] and the previous correction note [2]. The correct statement is as follows:

\section{Acknowledgements}

We thank Yvonne Sauermann for preparing the tastant solutions. The present work was carried out by Ms. Schalk in order to meet the requirements for the awarding of the title of Dr. med. at FAU. Ms. Schalk acquired some

The online version of the original article can be found at https://doi.org/ 10.1007/s00520-017-3898-y

\section{Y. Zopf}

yurdaguel.zopf@uk-erlangen.de

1 Hector Center for Nutrition, Exercise and Sports, Department of Medicine 1, Friedrich-Alexander-University Erlangen-Nuremberg, Ulmenweg 18, D-91054 Erlangen, Germany

2 Department of Medical and Life Sciences, Furtwangen University, Jakob-Kienzle-Str. 17, D-78054, VS-, Schwenningen, Germany

3 Department of Chemistry and Pharmacy, Emil Fischer Centre, Friedrich-Alexander-Universität Erlangen-Nuremberg, Henkestr. 9, D-91054 Erlangen, Germany

4 Department of Medicine 1, Friedrich-Alexander-University, Erlangen-Nuremberg, Ulmenweg 18, D-91054 Erlangen, Germany of the data together with Dr. Sarah Vogel. Data from both $\mathrm{PhD}$ theses were incorporated into the present publication.

\section{References}

1. Schalk P, Kohl M, Herrmann HJ, Schwappacher R, Rimmele M E, Buettner A, Siebler J, Neurath MF, Zopf Y (2018) Support Care Cancer 26: 843. 10.1007/s00520-017-3898-y

2. Schalk P, Kohl M, Herrmann HJ, Schwappacher R, Rimmele M E, Buettner A, Siebler J, Neurath MF, Zopf Y (2019) Support Care Cancer 27: 1579. 10.1007/s00520-019-4642-6

Publisher's note Springer Nature remains neutral with regard to jurisdictional claims in published maps and institutional affiliations. 